\title{
Factors Affecting the Structural Organization of Hemicyanine Chromoionophores in Langmuir Monolayers
}

\author{
Alexander V. Shokurov, Daria A. Silant'yeva, Vladimir V. Arslanov, \\ and Sofiya L. Selektor ${ }^{\circledR}$ \\ A.N. Frumkin Institute of Physical Chemistry and Electrochemistry of Russian Academy of Sciences, 119071 Moscow, Russia \\ ${ }^{\circledR}$ Corresponding authorE-mail: pcss_lab@mail.ru
}

\begin{abstract}
The present work deals with processes of structure-formation and aggregation behavior of hemicyanine chromoionophores in Langmuir monolayers and Langmuir-Blodgett films. It is revealed that the appearance of excimers upon compression of monolayers of these compounds is associated with cation-ionophore group interaction. The key role of the organic solvent in the preorganization of such monolayers on subphases containing indifferent cations is demonstrated. The extreme character of the dependence of the excimer formation efficiency on concentration of the above ions is shown, and optimum concentrations are identified.
\end{abstract}

Keywords: Langmuir monolayers, hemicyanines, excimers, fluorescence, aggregation, preorganization.

\section{Факторы, влияющие на структурную организацию гемицианиновых хромоионофоров в монослоях Аенгмюра}

\author{
А. В. Шокуров, А. А. Силантьева, В. В. Арсланов, С. А. Селектор ${ }^{\circledR}$ \\ ФГБУН Институт физической химии и электрохимии им. А.Н. Фрумкина РАН, 119071 Москва, Россия \\ ${ }^{\circledR}$ E-mail: pcss_lab@mail.ru
}

\begin{abstract}
Данная работа посвящена прочессам структурообразования и агрегаџионному поведению гемицианиновых хромоионофоров в монослоях Ленгмюра и пленках Ленгмюра-Блоджетт. Показано, что образование эксимеров при сжатии монослоев этих соединений связано с взаимодействием катион-ионофорных групп. Продемонстрирована ключевая роль органического растворителя в предорганизации таких монослоев на субфазах, содержащих индифферентные катионы. Установлен экстремальный характер зависимости эффективности образования эксимеров от концентрации упомянутых выме ионов, и определены их оптимальные коничентрации.
\end{abstract}

Ключевые слова: Монослои Ленгмюра, гемицианины, эксимеры, флуоресценция, агрегация, предорганизация.

\section{Introduction}

The search for methods of control of physico-chemical properties, and therefore, functional characteristics of molecular ensembles, is one of the most important problems of supramolecular chemistry and nanotechnology.

Langmuir monolayers and Langmuir-Blodgett films (LBF) based on hemicyanine dye derivatives are the subject of intensive research in the last decades ${ }^{[1-16]}$ due to the unique optic and fluorescent properties of these compounds and structural features of two-dimensional systems based on them. The ability of hemicyanines to form aggregates of various types, which, in their turn, significantly affect optical, thermal, and mechanical properties of organized monolayers, is of special interest. For example, ultrathin films of such compounds are used in molecular switchers and sensitive elements of sensors. ${ }^{[12-15,17-19]}$ One of the necessary conditions for application of such systems is the possibility 
to form organized and densely packed films on solid substrates. ${ }^{[20]}$ For amphiphilic compounds, this can be done by Langmuir-Blodgett technique, which allows control of the organization of precursor-monolayer on molecular level. In this regard, hemicyanines possess one important advantage: easiness of chemical modification by alkyl substituents, which provide these compounds with amphiphility that is required for formation of stable Langmuir monolayers at air/ water interface.

The study of aggregation behaviour of hemicyanine chromophores have shown a correlation of chemical structure of molecules and their supramolecular organization with optical properties of ultrathin films produced from them. ${ }^{[3,11,16,21-28]}$ Control of the structure and structuredependent properties of ultrathin films of hemicyanine derivatives should allow the realization of the advantages of planar supramolecular systems as the basic elements of nano-sized information devices. ${ }^{[14,26,29-31]}$ Therefore, LBF of hemicyanine dyes are of interest both from the standpoint of creating artificial functionalized membranes for accumulation and conversion of light energy into different information signals, ${ }^{[32]}$ and as convenient model systems for the development of approaches for the production of materials with desired properties. ${ }^{[16]}$

\section{Experimental}

All chemicals used were of analytical-reagent grade. Chloroform (Merck, extra-pure grade) was used as solvent. Barium, calcium, sodium, potassium, and magnesium perchlorates $\left(\mathrm{Ba}\left(\mathrm{ClO}_{4}\right)_{2}, \mathrm{Ca}\left(\mathrm{ClO}_{4}\right)_{2}, \quad \mathrm{NaClO}_{4}, \quad \mathrm{KClO}_{4}, \quad\right.$ and $\mathrm{Mg}\left(\mathrm{ClO}_{4}\right)_{2}$, respectively) were purchased from Sigma-Aldrich. Ultrapure water (18 $\mathrm{M} \Omega \cdot \mathrm{cm}, \mathrm{pH} 5.6)$ deionized with a Vodolei apparatus (NPP Khimelektronika) was used as subphase for Langmuir monolayers and LB transfers.

4-[4-(Dimethylamino)styryl]-1-docosylpyrimidium bromide (ChIP3, Figure 1b) was purchased from Sigma-Aldrich (France). The derivative hemicyanine dyes (ChIP1 and ChIP2, Figure 1a) have been synthesized by Dr. E.V. Lukovskaya at Moscow State University according to the previously described synthesis. ${ }^{[30,33]}$

Monolayer compression isotherms were recorded using the KSV mini-trough (Finland) made of Teflon and equipped with polyacetal barriers. Monolayer surface pressure was measured using a platinum Wilhelmy plate at a constant temperature of $20 \pm 1{ }^{\circ} \mathrm{C}$. Ultrathin films on solid substrates were obtained using the standard LB procedure: the monolayer was compressed to the required surface pressure, which was then kept constant. The substrate, previously immerged into the subphase perpendicularly to the air-water interface, was withdrawn from the subphase at a constant rate of $5 \mathrm{~mm} \cdot \mathrm{min}^{-1}$.

During the compression, UV-Vis differential reflectionabsorption and fluorescence spectra of hemicyanine monolayers were obtained using an AvaSpec-2048 fiber-optic spectrophotometer.
UV-Vis measurements were carried out at normal incidence. ${ }^{[34]}$ For fluorescence measurements, the UV-Vis reflectometric probe with a fiber diameter of $600 \mathrm{~mm}$ was also placed perpendicularly at 2-3 mm to the monolayer surface. Additional light-emitting diodes were used with an emission band as close as possible to the principal absorption band of the dye molecules in the monolayer. The light-emitting diodes were placed directly above the monolayer to ensure a $45^{\circ}$ angle of incidence of the exciting light on the subphase surface.

For LB film deposition, the silica plate was immersed into the Langmuir trough, perpendicular to the interface, before spreading the hemicyanine chloroform solution. The monolayer was compressed to the desired surface pressure, which was kept constant by means of a control system permanently adapting the monolayer surface. In the case of hemicyanine monolayers, the surface pressure decreased slightly during the period of 10-15 min, which is attributed to a reorganization of molecules at the airwater interface. After this stabilization period, the silica plate was removed from the water at a constant speed of $20 \mathrm{~mm} \cdot \mathrm{min}^{-1}$, which resulted in a hemicyanine monolayer being transferred on both sides of the plate.

All of these experiments were performed under red light, in order to limit undesired photoreactions. Absorption and fluorescence emission spectra of LB films were acquired with the Shimadzu 2450 PC spectrophotometer and the Shimadzu 5301-RF spectrofluorimeter, respectively.

In this work, Brewster microscope manufactured by KSV NIMA (Finland) was used for study of monolayer structure. The light source was a helium-neon laser class IIIb $(632.8 \mathrm{~nm})$ with a power of $10 \mathrm{~mW}$. The beam from the source passes through a polarizer and $p$-polarized beam falls on the water surface at the Brewster angle of the subphase. The reflected beam goes through the lens with a tenfold magnification to the USB-camera, which transmits the data via the interface module to the computer. Microscope is fixed on the frame above Langmuir trough in such a way that the laser beam would fall in the center of the trough.

Fluorescence microscopy photomicrographs were obtained as follows. The quartz plate coated with a studied monolayer was installed on the platform of vertical microscope (BX51WI, Olympus), equipped with a mercury lamp (U_LH100HG) with power of $100 \mathrm{~W}, \mathrm{BX}$ RFA lamp and cube filter U MWBV2 (excitation in the range of $400-440 \mathrm{~nm}$, emission above $475 \mathrm{~nm}$ ) or U_MNB2 (excitation in the range of $470-490 \mathrm{~nm}$, emission above $520 \mathrm{~nm})$. Lenses LMPF $1 \times 10, \times 20$, and $\times 50$ were used for imaging. Photomicrographs were obtained using Color View II CCD (SIS Germany) camera. Signal accumulation time usually was from 1 to 5 seconds. At least three images have been recorded at seven different points for each monolayer. Resolution capacity of the device was in the range $0.4-0.6$ microns due to the high numerical aperture of the lenses.

\section{Results and Discussion}

In the present work, we studied the structure and optical properties of Langmuir monolayers of amphiphilic crown substituted hemicyanine chromoionophores during

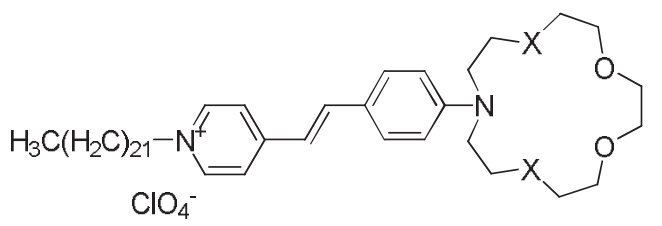

(a)

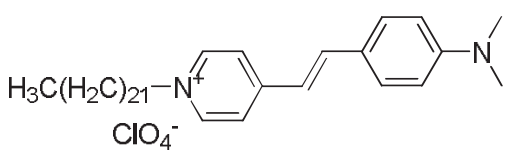

(b)

Figure 1. Chemical structure of molecules (a) ChIP1 $(X=O)$, ChIP2 $(X=S)$ and (b) ChIP3. 
their formation and compression on aqueous subphases containing different quantity $(0-10 \mathrm{mM})$ of alkali and alkaline earth metal cations. The studied compounds consisted of hemicyanine chromophore functionalized by hydrophobic alkyl substituent with a length of 22 carbon atoms, and also by ionophore group of different structure: aza-15-crown-5 for ChIP1, di-thia-aza-15-crown-5 for ChIP2, and dimethylamine for ChIP 3 (Figure 1).

Previously we have shown ${ }^{[29,31]}$ that a reversible formation of excimers is possible in the monolayers of studied compounds in the presence of "inert" cations in the subphase, which inhibit stacking aggregation. However, the question on the influence of the type of cations and their concentration in the subphase on the efficiency of the formation of such fluorescent dimers in the monolayer remained unstudied so far.

As it has been shown previously, ${ }^{[31]}$ compression of ChIP1 monolayer, formed on the deionized water surface only leads to a gradual quenching of fluorescence. While in

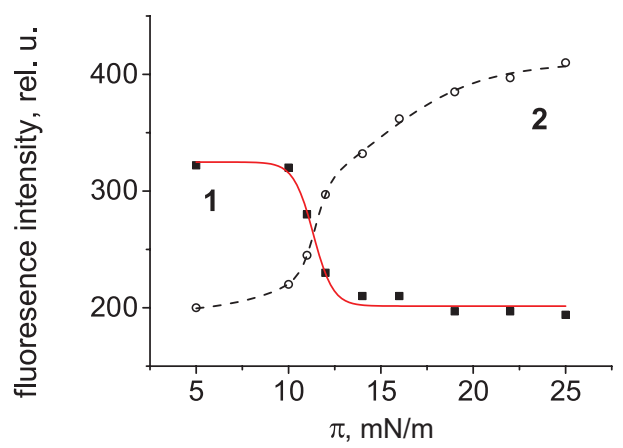

Figure 2. Dependence of fluorescence intensity on surface pressure for the monolayer of ChIP1 on the surface of (1) deionized water (monomers, $600 \mathrm{~nm}$ ) and (2) barium perchlorate solution (excimers, $700 \mathrm{~nm}$ ). the case of the same monolayer on the surface of the barium perchlorate solution, the intensity of the initial monomer fluorescence bands also decreases, but the growth of intense emission band around $700 \mathrm{~nm}$, corresponding to the emission of investigated hemicyanine dye excimers is being observed (Figure 2).

A characteristic spectral change corresponding to the formation of "head-to-tail"-type dimers was observed upon compression of the monolayer on the surface of deionized water. ${ }^{[29,31]}$ While the presence of barium cations in concentration of $1 \mathrm{mM}$ inhibits this intermolecular interaction and promotes co-directional orientation of the molecules in the aggregates at the interface. ${ }^{[29]}$

In this study, a more detailed investigation of the differences in organization of ChIP1 monolayers, formed on the deionized water and barium perchlorate solution, was conducted by Brewster angle microscopy method. The obtained photomicrographs show that spreading of a dilute solution of the studied compounds in chloroform onto the surface of pure water produces expanded monolayer containing some large individual associates (Figure 3a). Once surface pressure starts to increase upon compression, monolayer appears homogenized in photomicrographs. As the surface pressure in the monolayer on the surface of deionized water increases, formation of some aggregated associates takes place, which form a new homogeneous structure at high pressures (Figure 3a).

The results obtained under the same conditions for ChIP1 monolayer formed on the subphase containing $1 \mathrm{mM}$ of $\mathrm{Ba}^{2+}$ cations confirm the changes in the monolayer structure, which occur as a result changing of the subphase composition. Noticeable enlargement of aggregates compared to a monolayer on deionized water is observed upon compression of the chromoionophore monolayer. Such large aggregates also form their own homogeneous structure at high surface pressures (Figure 3b). (a)
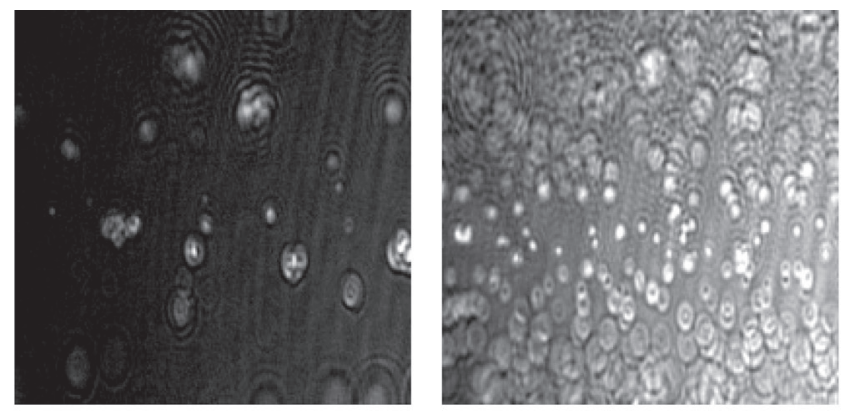

(b)

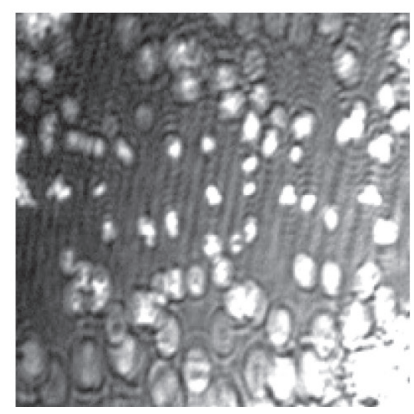

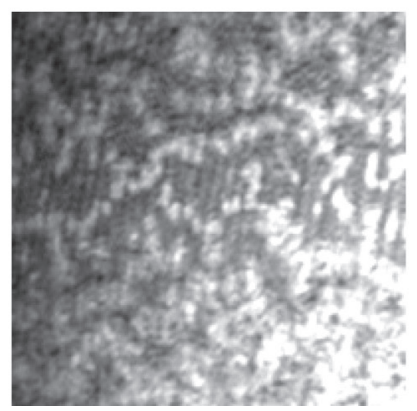
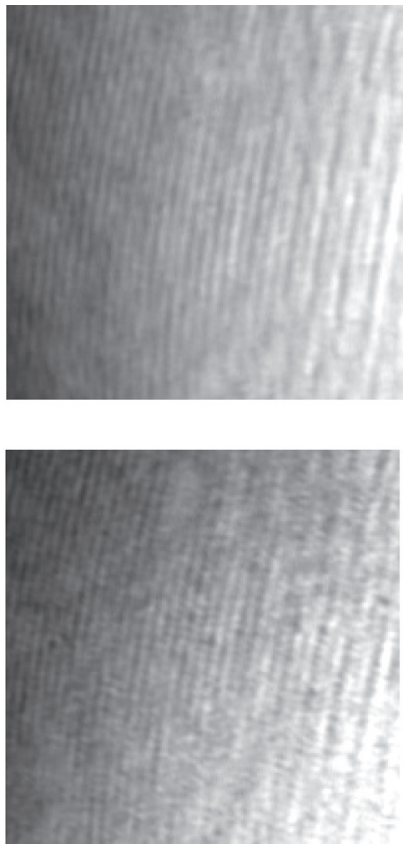

Figure 3. Photomicrographs obtained by Brewster angle microscopy technique for monolayer of ChIP1 at surface pressure of 1, 10, and $25 \mathrm{mN} / \mathrm{m}$ (from left to right) on (a) deionized water and (b) on surface of $1 \mathrm{mM}$ solution of $\mathrm{Ba}\left(\mathrm{ClO}_{4}\right)_{2}$ (image size $200 \times 200 \mu \mathrm{m}$ ). 
Thus, Brewster angle microscopy, which allows one to track changes in the monolayer directly in the process of its formation, also confirms the changes of monolayer structure in the presence of barium cations in the subphase.

Moreover, upon the expansion of the ChIP1 monolayer, formed on barium perchlorate solution, after its compression to a surface pressure of $35 \mathrm{mN} / \mathrm{m}$, only a small hysteresis is observed in the isotherm (Figure 4). At the same time, the monomer emission appears again on the fluorescence spectra of such expanded monolayer, which indicates the reversibility of the observed transformations.

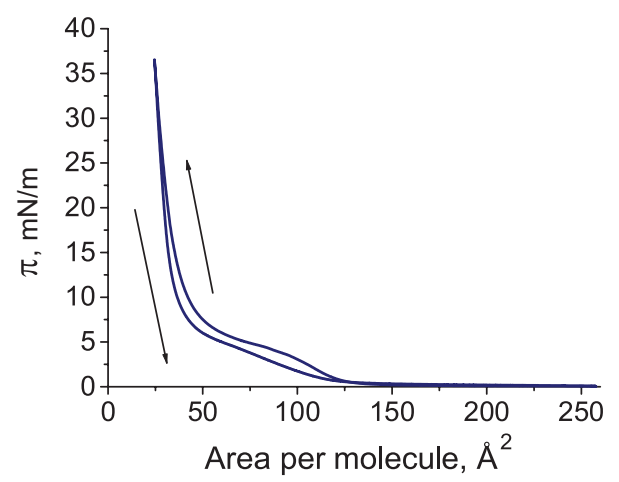

Figure 4. Hysteresis of compression isotherms of ChIP1 monolayer on $1 \mathrm{mM} \mathrm{Ba}\left(\mathrm{ClO}_{4}\right)_{2}$ solution.

Earlier $^{[29,31]}$ we have made a hypothesis that preorganization of ChIP1 monolayer due to interaction with barium cations occurs at the first stage of monolayer formation - upon application of the solution onto the surface of the subphase and its spreading - even before the solvent completely evaporates. To confirm this hypothesis and elucidate the role of the solvent in the observed changes, a monolayer of the studied compound was formed on the surface of deionized water, and barium perchlorate solution was introduced under this monolayer only after evaporation of the solvent (Figure 5a). The fluorescence spectra obtained in this experiment indicate no formation of excimers: compression of the monolayer and increase of the surface pressure leads only to a decrease in fluorescence intensity of only the monomeric form of the compound, as in the case of the monolayer on the surface of deionized water. Observed significant reduction in the monomer fluorescence intensity with increase of surface pressure is, apparently, a consequence of stacking-aggregation of molecules upon compression of the monolayer (Figure 5b). Therefore, as we have suggested, the possibility of excimer formation at the air/barium perchlorate solution interface is determined by the presence of chloroform, which ensures possibility of interaction of non-hydrated crown ether groups of the dye with metal cations during application of chromoionophore solution on the surface of the cation-containing subphase at the initial stage of the monolayer formation.

As we have shown previously, ${ }^{[31]}$ excimers may appear upon compression in ChIP1 monolayers formed on subphases containing cations of alkali and alkaline earth metals $\left(\mathrm{Ba}^{2+}, \mathrm{Ca}^{2+}, \mathrm{Mg}^{2+}\right.$, and $\left.\mathrm{K}^{+}\right)$. Detailed studies of fluorescence spectra of monolayers during its compression on the subphases of different composition carried out in this work revealed that efficient excimer formation occurs in a certain concentration range for every cation. The dependences of the relative fluorescence intensity of the excimers (the ratio of the emission intensity of the excimer band (about $700 \mathrm{~nm}$ ) in the compressed monolayer ( $\pi$ about $30 \mathrm{mN} / \mathrm{m}$ ) to the intensity of emission of the monomers (about $600 \mathrm{~nm}$ ) in the expanded monolayer on cation concentration for different cations are show in Figure 6. It can be seen that in all cases these dependences in the concentration range from 0 to $5 \mathrm{mM}$ are of extreme character and each of the investigated cations can be characterized by value of its own optimal concentration corresponding to the maximum relative fluorescence intensity of excimers in the monolayer. For example, in the case of ChIP1 this value for calcium amounted to $0.1 \mathrm{mM}$, for barium $-1 \mathrm{mM}$, for magnesium about $2 \mathrm{mM}$, and for potassium - about $5 \mathrm{mM}$ (Figure 6). Moreover, the increase of the cations concentration in the subphase ultimately leads to the disappearance of the longwavelength emission (about $700 \mathrm{~nm}$ ) band in all considered systems (Figure 6). Characteristically, the relative fluorescence intensity of excimers increases with increasing surface pressure in the monolayer (Figure 7). In addition, the comparison of results obtained for $\mathrm{Ba}^{2+}, \mathrm{Ca}^{2+}, \mathrm{Mg}^{2+}$, and $\mathrm{K}^{+}$ cations have shown that the optimal concentration of a cat-
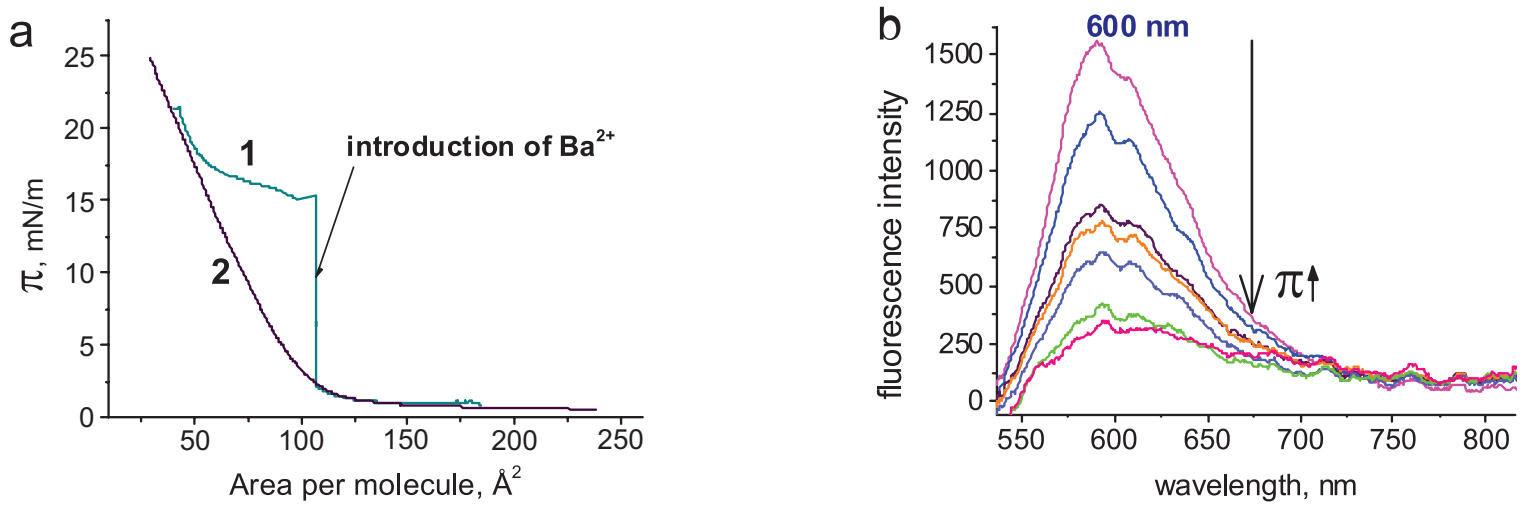

Figure 5. (a) Compression isotherm of ChIP1 monolayer upon introduction of barium cations after solvent evaporation (1) and upon formation of the monolayer on the subphase already containing barium perchlorate (2). (b) ChIP1 monolayer fluorescence spectra during compression in the case of cation introduction after solvent evaporation. 
ion corresponding to the maximum efficiency of excimer formation in the monolayer decreases with increasing of cation binding constant (in the row $\mathrm{K}^{+} \rightarrow \mathrm{Mg}^{2+} \rightarrow \mathrm{Ba}^{2+} \rightarrow \mathrm{Ca}^{2+}$ ). ${ }^{[35]}$ The similarity of obtained dependences and coincidence of fluorescence parameters for monolayers formed in the presence of various cations indicate the identical nature of the cation-ligand interaction processes.

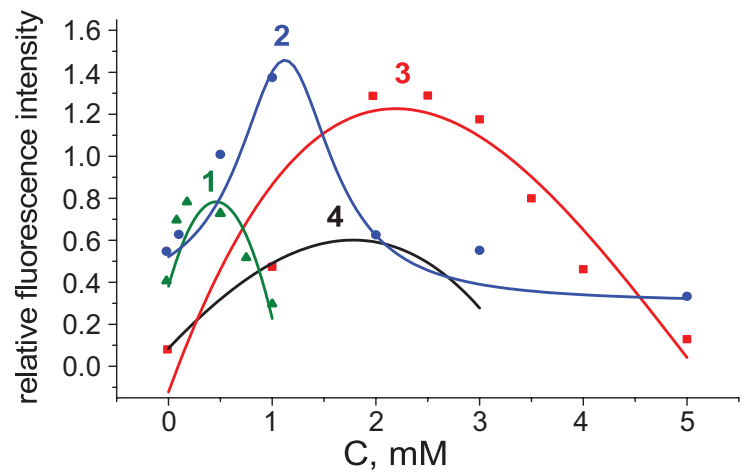

Figure 6. Dependence of relative intensity of excimers fluorescence on cation concentration in the subphase: (1) $\mathrm{Ca}^{2+}$, (2) $\mathrm{Ba}^{2+}$, (3) $\mathrm{K}^{+}$, (4) $\mathrm{Mg}^{2+}$.

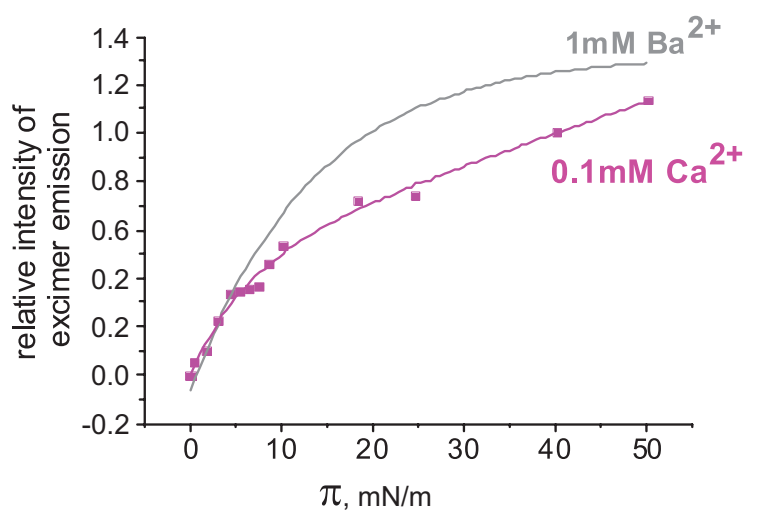

Figure 7. Dependence of relative intensity of excimer fluorescence $\left(I_{700} / I_{600}\right)$ on the surface pressure.
To reveal the role of the ionophore group in the studied process, we have chosen 3 hemicyanine dyes (ChIP1, ChIP2, ChIP3), differing only in the composition of the ionophore group, and arranged them in a series, in which the affinity between the ionophore substituent and cations of alkaline earth metals in the subphase increases in the following sequence: ChIP3 - ChIP1 - ChIP2. In situ spectral studies of Langmuir monolayers using fiber-optic UV-Vis spectroscopy showed that in all three cases the compression of the monolayer on the deionized water is accompanied by intensive formation of stacking-aggregates, and the presence of indifferent cations, which do not form stable complexes with the ionophore group of the dye, in the subphase inhibits the head-to-tail-type aggregation.

Registration of fluorescence spectra of monolayers of the considered series of compounds during their compression on the subphases of different composition has allowed us to establish that there is a range of concentrations of perchlorates of alkaline earth metals for each of the three dyes, in which formation of excimers in the monolayer is observed. Moreover, for every compound the dependence of excimer fluorescence intensity on $\mathrm{Ba}^{2+}$ cation concentration has a maximum at different cation concentration.

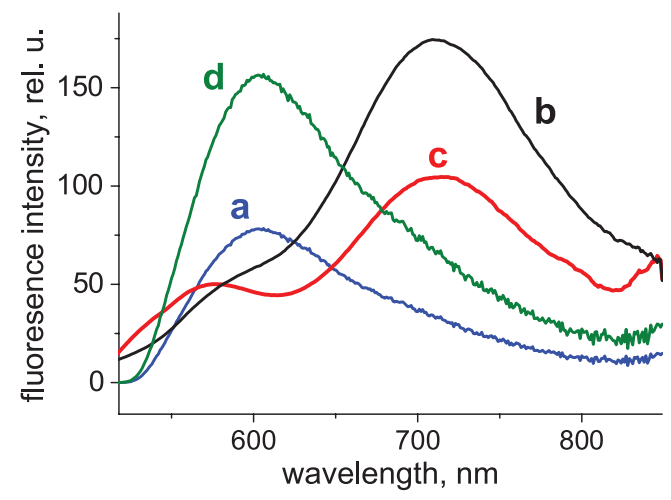

Figure 8. Fluorescence spectra of ChIP1 LBFs transferred from surface of (a) deionized water, and aqua solutions of barium perchlorate with the concentrations of (b) $1 \mathrm{mM}$, (c) $3 \mathrm{mM}$, and (d) $10 \mathrm{mM}$.

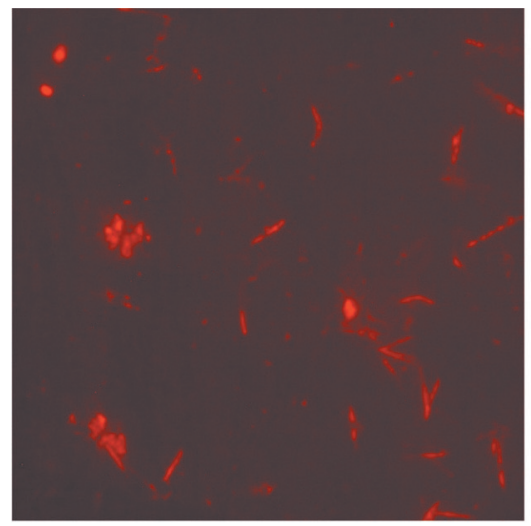

a

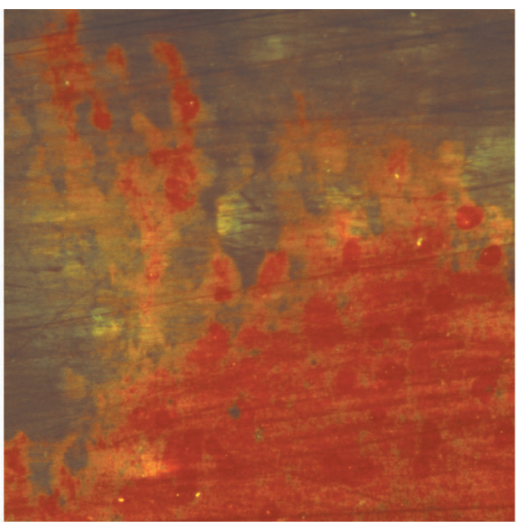

b

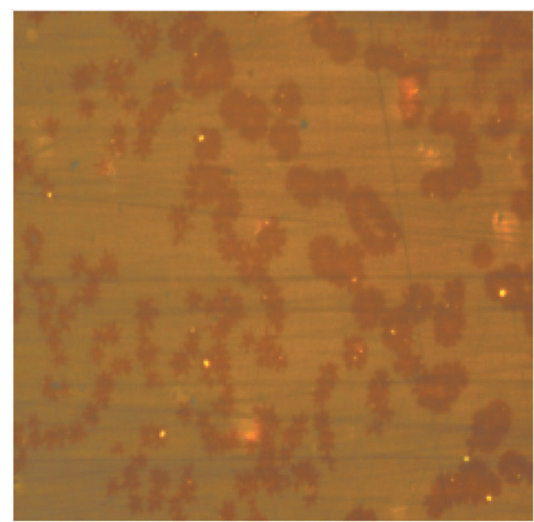

c

Figure 9. Fluorescent photomicrographs of ChIP1 LBF formed at barium perchlorate content in the subphase of (a) $1 \mathrm{mM}$, (b) $3 \mathrm{mM}$, (c) $10 \mathrm{mM}$ (image size $250 \times 250 \mu \mathrm{m}$ ). 
Replacement of the oxygen azacrown ether by dithiaaza crown ether leads to reduction of the optimal concentration of barium perchlorate subphase by an order of magnitude (from $1 \mathrm{mM}$ to $0.1 \mathrm{mM}$ ), and for ChIP3, which does not have crown ether moiety whatsoever, this value is more than $3 \mathrm{mM}$. Thus, the optimal concentration of the cations in the subphase that provides the most efficient formation of excimers is decreasing in the same sequence, in which the affinity between the ionophore substituent and metal cations in the subphase increases: ChIP3 - ChIP1 - ChIP2.

The concept that the formation of excimers is associated with cation-ionophore interactions is in good agreement with the above described results of studies on the role of chloroform in aggregation processes in the studied system, since the efficiency of these interactions is known to be significantly higher in organic environments than in aqueous ones. The presence of the maximum in the curves of dependence of the relative excimer fluorescence intensity on concentration of metal cations in the aqueous subphase appears to be due to the formation of short-lived sandwich complexes of 1:2 composition (1 cation per 2 ligand molecules). Such complexes formed at a certain cation concentration can "define" the structural organization of the monolayer, at the initial stage of monolayer formation. Increase of the cation content above this optimal concentration leads to the formation of complexes of 1:1 composition, the mutual repulsion of which inhibits the formation of excimers.

Thus, the appearance of excimers upon compression of monolayers of studied hemicyanine chromoionophores is associated with cation-ionophore group interaction occurring in the presence of an organic solvent at the initial stage of monolayer formation.

With the example of barium cations, we investigated fluorescent characteristics of ChIP1 LBF transferred from the subphases with different concentrations of cations. At concentration corresponding to the maximum of the dependence of the relative excimer fluorescence intensity on cation concentration in the subphase, LBF fluorescence spectra contain one distinct long-wavelength band (about $700 \mathrm{~nm}$ ). The position of the emission band of the film, transferred from the subphase with a high concentration of barium cations $(10 \mathrm{mM})$ coincides with those observed for the film obtained from a monolayer on the surface of deionized water. Furthermore, the spectrum of the film produced from monolayer formed on the surface of the barium perchlorate solution with concentration of $3 \mathrm{mM}$ contains both monomer and excimer emission bands (Figure 8). These results confirm the preservation of the structural features of monolayers of amphiphilic hemicyanine chromo-fluoroionophores upon their transfer onto the solid substrate by Langmuir-Blodgett technic.

Such behavior of LBFs transferred from subphases with different content of barium cations is also recorded by fluorescence microscopy. A spatial separation of areas emitting light of different wavelengths $(600 \mathrm{~nm}$ for monomer and $700 \mathrm{~nm}$ for excimer) upon photoexcitation can be seen in the photomicrographs (Figure 9).

Considering the high sensitivity of the studied compounds to the conditions of monolayer spreading, ${ }^{[28]}$ the observed structural separation may serve as indirect confirmation of the assumption of the role of the phantom sandwich complexes as associate nuclei upon structure formation in the monolayer.

\section{Conclusions}

The key role of chloroform in the process of preorganization of ChIP1 monolayer due to the inhibition of the stacking aggregation process in the monolayer is revealed. The solvation of crown ether fragment by organic solvent allows the ionophore group to effectively interact with metal cations from the subphase. Such interaction cannot occur in the absence of chloroform, when a crown ether is solvated by water molecules.

It is shown that the optimal concentration of the cations of alkali and alkaline earth metals in the subphase corresponding to the maximum efficiency of excimers formation in the monolayer decreases with increasing cation binding constant. Moreover, replacement of oxygen azacrown ether moiety by azadithiacrown ether reduces the optimal concentration of barium perchlorate in the subphase by an order of magnitude.

Acknowledgements. The present work was financially supported by Russian Foundation for Basic research, grants No. 16-33-60024 mol a dk, 16-29-05284 ofi_m, 16-29-05272 ofi_m, and 16-03-00538 a.

\section{References}

1. Kajikawa K., Shirota K., Takezoe H., Fukuda A. Jpn. J. Appl. Phys. 1990, 29, 913-917.

2. Kajikawa K., Shirota K., Takezoe H., Fukuda A. Jpn. J. Appl. Phys. 1991, 30, 362-365.

3. Carpenter M.A., Willand C.S., Penner T.L., Williams D.J., Mukamel S. J. Phys. Chem. 1992, 96, 2801-2804.

4. Hall R.A., Thistlethwaite P.J., Grieser F., Kimizuka N., Kunitake T. Colloids Surf., A 1995, 103, 167-172.

5. Ma S., Lu X., Han K., Liu L., Wang W., Zhang Z., Zhang Z., Zhong J. Thin Solid Films 1995, 256, 215-219.

6. Lang A.-D., Zhai J., Huang C.-H., Gan L.-B., Zhao Y.-L., Zhou D.-J., Chen Z.-D. J. Phys. Chem. B 1998, 102, 1424-1429.

7. Niidome Y., Ayukawa H., Yamada S. J. Photochem. Photobiol., A 2000, 132, 75-80.

8. Wang Z., Huang Y., Huang C., Zheng J., Cheng H., Tian S. Synth. Met. 2000, 114, 201-207.

9. Wang W., Lu X., Xu J., Jiang Y., Liu X., Wang G. Phys. B 2000, 293, 6-10.

10. Chandra M.S., Ogata Y., Kawamata J., Radhakrishnan T.P. Langmuir 2003, 19, 10124-10127.

11. Rajesh K., Chandra M.S., Hirakawa S., Kawamata J., Radhakrishnan T.P. Langmuir 2007, 23, 8560-8568.

12. Tatay S., Gaviña, P., Coronado E., Palomares E. Org. Lett. 2006, 8, 3857-3860.

13. Shiraishi Y., Miyamoto R., Hirai T. Langmuir 2008, 24, 42734279.

14. Rivera L., Puyol M., Miltsov S., Alonso J. Anal. Bioanal. Chem. 2007, 387, 2111-2119.

15. Bricks J.L., Slominskii J.L., Kudinova M.A., Tolmachev A.I., Rurack K., Resch-Genger U., Rettig W. J. Photochem. Photobiol., A Chem. 2000, 132, 193-208.

16. Lambacher A., Fromherz P. J. Phys. Chem. B 2001, 105, $343-$ 346. 
17. Soper S.A., Mattingly Q.L. J. Am. Chem. Soc. 1994, 116, 3744-3752.

18. Das S., Thomas K.G., Thomas K.J., Kamat P.V., George M.V. J. Phys. Chem. 1994, 98, 9291-9296.

19. Wijekoon W.M.K.P., Park C.K., Prasad P.N. In: Proc. SPIE, Conference Vol. 2285, Nonlinear Optical Properties of Organic Materials VII, September 23, 1994. p. 254-261.

20. Ledoux I., Josse D., Fremaux P., Piel J.-P., Post G., Zyss J., McLean T., Hann R.A., Gordon P.F., Allen S. Thin Solid Films 1988, 160, 217-230.

21. Spano F.C., Mukamel S. Phys. Rev. Lett. 1991, 66, 1197-1200.

22. Tkachev V.A., Tolmachev A.V., Chernigov L.V., Lakin E.E. Ukr. Fiz. Zh. 1993, 38, 1220-1226.

23. Schildkraut J.S., Penner T.L., Willand C.S., Ulman A. Opt. Lett. 1988, 13, 134-136.

24. Anceau C., Brasselet S., Zyss J. Chem. Phys. Lett. 2005, 411, 98-102.

25. Han K., Wang Q., Tang G., Li H., Sheng X., Huang Z. Thin Solid Films 2005, 476, 152-156.

26. Mishra A., Behera R.K., Behera P.K., Mishra B.K., Behera G.B. Chem. Rev. 2000, 100, 1973-2011.
27. Abraham E., Grauby-Heywang C., Selector S., Jonusauskas G. J. Photochem. Photobiol. B 2008, 93, 44-52.

28. Grauby-Heywang C., Selector S., Abraham E., Jonusauskas G. Prot. Met. Phys. Chem. Surf. 2011, 47, 31-38.

29. Selektor S.L., Shcherbina M.A., Bakirov A.V., Batat P., Grauby-Heywang C., Grigorian S., Arslanov V.V., Chvalun S.N. Langmuir 2016, 32, 637-643.

30. Selektor S.L., Raitman O.A., Silant'eva D.A., Ivanova N.V., Jonusauskas G., Lukovskaya E.V., Batat P., Arslanov V.V. Prot. Met. Phys. Chem. Surf. 2011, 47, 484-493.

31. Batat P., Grauby-Heywang C., Selektor S., Silantyeva D., Arslanov V., McClenaghan N., Jonusauskas G. ChemPhysChem 2014, 15, 2823-2833.

32. Dix J.P., Voegtle F. Chemische Berichte 1980, 113, 457-470.

33. Huang Y., Cheng T., Li F., Huang C.-H., Hou T., Yu A., Zhao X., Xu X. J. Phys. Chem. B 2002, 106, 1002010030.

34. Stuchebryukov S.D., Selektor S.L., Silantieva D.A., Shokurov A.V. Prot. Met. Phys. Chem. Surf. 2013, 49, 189-197.

35. Mitewa M., Mateeva N., Antonov L., Deligeorgiev T. Dyes Pigm. 1995, 27, 219-225. 